\title{
The Students Ability of Expressing Generality in Numbers at Junior High School Based on School Level
}

\author{
$1^{\text {st }}$ Yumiati \\ Mathematics Education Department \\ Indonesia Open University \\ Bengkulu, Indonesia \\ yumi@ecampus.ut.ac.id
}

\author{
$2^{\text {nd }}$ Saleh Haji \\ Mathematics Education Department \\ Bengkulu University \\ Bengkulu, Indonesia \\ salehhaji@unib.ac.id
}

\begin{abstract}
This study aims to determine the ability of expressing generality of junior high school students on the topic of numbers based on school level. To achieve the objective descriptive research with the subjects of the study were 8th grade students at high, middle, and low junior high school, amounting to 123 people in Pamulang District South Tangerang. Methods of data collection using test methods. School level is a school ranking based on school accreditation from the Tangerang City Education Office.The results of the research are as follows: 1) The score of students' ability in expressing generality in numbers at higher schools level is greater than students in low and middle school level; 2) The score of students' ability in expressing generality in numbers at middle and low school level did not differ significantly; and 3) The score of students' ability in expressing generality in numbers at all school levels are in enough categories.
\end{abstract}

Keywords- Expressing generality in numbers; School level

\section{INTRODUCTION}

Dowker [1] explains that the problem of learning difficulties in mathematics is a major problem in learning mathematics. Because this can hamper the achievement of learning objectives in school mathematics. The problem is mostly experienced by most students at school [2] and [3]. At least there are 2 problems faced by students in learning mathematics is a problem related to addition and multiplication operations [4]. Quantitatively, students' difficulties in learning mathematics are presented by Hughes [5] which explains that only $60 \%$ of students can perform mathematical calculations correctly on real-life solutions. In addition to the operational aspects, students' weaknesses are also in terms of conceptual understanding, as in the understanding of the equivalent concept, between equations $x+42=77$ with $x=77-42$ [6] and [7]. These errors lead to student weaknesses in expressing generality in numbers. Students can not disclose and associate the concept of numbers with other concepts correctly.

Mason, Graham, and Willder [8] classify expressing generality into three parts: 1) expressing generality in numbers; 2) expressing generality in diagrams; and 3) expressing generality in outside school. The problem in this research will focus on expressing generality in numbers, because the position of numbers is very important in mathematics. Number is one of the basic topics in mathematics. In particular the problem formulation in this research is how is the quality of expressing generality ability of junior high school students based on school level?

The Students Abilty of Expressing Generality in Numbers in Thingking Algebraic

Mason, Graham, and Wilder [8], algebra as a language of expression if they perceive and express generalities for themselves. As a language, Algebra can convey the message of generalization results from various special objects. As well as being a language, Algebra can also be viewed as an activity, a way of thinking, as a culture, a tool, an arithmetic generalization, and as a lesson. Kieran [9] describes algebra as follows: 1) Algebra is an activity; 2) Algebra is a way of thinking; 3) Algebra is a culture; 4) Algebra is a language; 5) Algebra is a tool; 6) Algebra is a generalized arithmetic; and 7) Algebra is a school subject.

The process of understanding algebra is done through students' thinking activities. The activity is algebra thinking. Kieran [9] explains thinking algebra is a mathematical thinking that involves the development of reasoning, building meaning for symbols and counting operations. Meanwhile, Kriegler [10], states that algebraic thinking is a mathematical thinking related to reasoning, representation, and problem solving. The activity of representation of an idea to build a meaning from the idea is manifested in expressing generality as a form of general mathematical presentation of special mathematical forms. Through the activities of mathematical thinking (algebra) can effectively help students to understand mathematics material well [11].

According to Chua [12], the idea behind these generalizing problems is that students are expected to recognize, recognize, extend and articulate the pattern. According to Mason, Burton, and Stacey [13], generalizations are the life-blood of mathematics. Generalizing starts when you sense an underlying 
pattern. Generalizing means to detect a pattern that is likely to be true, and where it is likely to be true.

The theory of expressing generality contains the ability to construct patterns from a phenomenon, but the reality in the field of many students who have not mastered in composing a pattern of a mathematical phenomenon.

Mason, Graham, and Wilder [8] explained that Algebra provides a system of symbols and languages that can be manipulated to express numbers and manipulate the generality. Expressing generaliity in algebraic thinking consists of: 1). Expressing generality in numbers; 2). Expressing generality in diagrams and drawings; 3) Exprssing generality in terms of mathematical relationships with everyday life.

Expressing generality in numbers, such as expressing in the number pattern (Number Patterns) is $4+6=6+4$. Based on the pattern of numbers can be formed equivalent equations ie $3+5=5+3 ; 2+4=$ $4+2 ; 1+3=3+1$ and so on. Similarly, the pattern of numbers on the sum of two consecutive numbers follows.

$$
\begin{aligned}
& 1+2=(2 \times 1)+1 \\
& 2+3=(2 \times 2)+1 \\
& 3+4=(2 \times 3)+1
\end{aligned}
$$

$$
\text { and so on, so } 54+55=(2 \times 54)+1
$$

Mason, Graham, and Wilder [8] give an example of expressing generality in the following pattern of numbers:

$$
\begin{aligned}
& (3+2) \times(3-2)=3^{2}-4 \\
& (4+2) \times(4-2)=4^{2}-4 \\
& (5+2) \times(5-2)=5^{2}-4
\end{aligned}
$$

According to Kilpatrick, Swafford, and Findell [14] there are two aspects to algebraic thinking: 1) Algebra as a systematic way of generalization expressions (arithmetic) and abstraction, and 2) Algebra as the transformation of syntax and symbols. According to Yumiati [7], the ability to think algebra developed in schools consists of: the ability of representation, transformation, generalization, and justification. The ability of representation is the ability of students in presenting an abstract concept in a more concrete form. Like, the representation of the concept of "three" is represented as " 3 " or "III" and others. The ability of transformation is the ability of students to change a form of concept into another form by using certain rules. Such as changing the form of equation $4 x+2 y=10$ to $2 x+y=5$. The ability of generalization is the ability to create a general form of a mathematical object of various objects that are special. Like, the commutative nature of multiplicity of two integers ie $a \times b=b \times a$ where $a$ and $b$ are integers. The generalization is derived from the following facts: $3 \times 5=\quad 5 \times 3=15,6 \times 4=4 \times$ $6=24,7 \times 2=2 \times 7=14$ and so on. The ability of justification is a student's ability to show the truth of a mathematical object. Like the ability to point out the truth of a statement, if $a=b$ and $b=\mathrm{c}$, then $a=c$.

The ability of expressing generality in numbers of students can be developed through algebra learning. According to Kieran [9], the model of algebra activity in schools is as follows: 1) Generational activity; 2) Transformational activity; and 3) Global / meta-level activity. The generational activity of algebra involves the formation of expressions and equations which are algebraic objects. As the formation of the equation $y=$ $x$ is formed from the relationship of $x$ and $y$ which causes $y=x$. Transformational activities consist of the activity of sorting an object, collecting objects, extending, replacing, adding, multiplying, exponential, simplifying, and equivalent. Global / meta-level activity is an activity that places algebra as a tool, but not exclusively for algebra. These activities are modeling, structure, change study, relationship analysis, verification, and estimation.

The weakness of algebraic thinking is caused by both internal and external factors. One of the internal factors is the students' motivation in learning algebra [9]. Teachers and parents are less motivational to students to learn algebra. While external factors, such as failure in the use of approaches on learning algebra [9]. This leads to less effective algebra learning. Students are less challenged to think algebra. Learning is more focused on teacher activity, not students. Thus causing weak ability of creative thinking of student [15].

.The research question is how is the student's ability in expressing generality in numbers based on school level in Tangerang city? The purpose of this research is to know the student's ability in expressing generality in numbers based on school level in Tangerang city. This study deepens from previous research findings about students' algebraic thinking abilities. Because expressing generality is part of algebra.

\section{RESEARCH METHODS}

This research is descriptive research, because want to describe student ability of expressing generality in numbers at SMP Pamulang District. Support from this approach comes from the research institutions, students, teachers, and education offices of the city of Tangerang. The subjects of this study were 8th grade students at high, middle, and low grade junior high. Each school level is selected by one school, and each school is selected 2 - 3 classes to be the subject of research.

The data of this research were obtained by using the test instrument of Expressing Generality in Numbers. The data in this research consists of quantitative and qualitative data. Quantitative data in the form of expressing generality capability test scores were analyzed statistically. Meanwhile, qualitative 
data in the form of analysis of student errors in solving the problem of expressing generality in numbers.

\section{RESULTS AND DISCUSSION}

Descriptive statistics on the ability score of expressing generality of students on the topic of numbers are presented in Table 1 below.

Table 1 Descriptive Statistics Scores Expressing Generality in Numbers

\begin{tabular}{|l|c|c|c|c|}
\hline \multirow{2}{*}{$\begin{array}{c}\text { Descriptive } \\
\text { Statistics }\end{array}$} & \multicolumn{3}{|c|}{ School Level } & \multirow{2}{*}{ Overall } \\
\cline { 2 - 4 }$N$ & Low & Middle & High & \\
\hline Max score & 32 & 48 & 43 & 123 \\
\hline Min score & 6.75 & 9.25 & 10 & 10 \\
\hline Mean & 0.25 & 1 & 2.75 & 0.25 \\
\hline$S D$ & 5.44 & 5.79 & 8.26 & 6.56 \\
\hline
\end{tabular}

Note:

Maximum score is ideal $=10$

Furthermore, the scores of students' expressing generality skills are grouped again based on mixed criteria of Benchmark Assessment and Normal Rating. Obtained groupings as follows.

Table 2 Criteria for Grouping Student Expressing Generality

\begin{tabular}{|l|l|}
\hline \multicolumn{1}{|c|}{ Criteria } & \multicolumn{1}{c|}{ Value Interval } \\
\hline Good & $\alpha \geq 8.40$ \\
\hline Medium & $4.72 \leq \alpha<8.40$ \\
\hline Less & $\alpha<4.72$ \\
\hline
\end{tabular}

Note:

$\alpha=$ Score ability expressing generality in numbers

Table 2 shows that the score of expressing generality of student numbers in high school is greater than that of students in middle and low schools. Similarly, the students' scores at the secondary school are greater than the students in the lower level. Based on grouping criteria such as table 2, the expressing generality score of students on the topic of numbers at all school levels and overall student is in medium category.

To test whether differences in students' expressing generality skills at three significant school levels were different, then a different test was conducted between the three school levels using the Kruskal-Wallis test and further tests using the Mann-Whitney test.

Normality test results show that not all data is normally distributed, thus testing using nonparametric test Kruskal-Wallis.

Table 3 Results of Kruskall-Wallis Student Score Test

\begin{tabular}{|l|c|c|c|}
\hline School level & $\boldsymbol{N}$ & Mean Rank & sig. (2-way) \\
\hline Low & 32 & 41.67 & \multirow{2}{*}{0.000} \\
\hline Middle & 48 & 46.07 & \\
\hline High & 43 & 94.91 & \\
\hline
\end{tabular}

Data in Table 3 shows that there is a significant difference in the ability of expressing generality of students on numbers at three different school levels.
High school students have the highest mean score and low-grade students have the lowest mean score. To find out whether the mean score of students' expressing generality ability across the school level differed significantly or not, a Mann-Whitney test was performed.

Table 4 Results of Mann-Whitney Test for Student Scores Among

\begin{tabular}{|c|c|c|c|c|}
\hline $\begin{array}{c}\text { School } \\
\text { Level }\end{array}$ & $\begin{array}{l}\text { U Mann } \\
\text { Whitney }\end{array}$ & $Z$ & $\begin{array}{c}\text { sig. } \\
\text { (1-way) }\end{array}$ & Note \\
\hline Low & \multirow{2}{*}{721.000} & \multirow{2}{*}{-0.464} & \multirow{2}{*}{0.322} & \multirow{2}{*}{$H_{0}$ accepted } \\
\hline Middle & & & & \\
\hline Low & \multirow{2}{*}{84.500} & \multirow{2}{*}{-6.520} & \multirow{2}{*}{0.000} & \multirow{2}{*}{$H_{0}$ rejected } \\
\hline High & & & & \\
\hline Middle & \multirow{2}{*}{220.500} & \multirow{2}{*}{-6.481} & \multirow{2}{*}{0.000} & \multirow{2}{*}{$H_{0}$ rejected } \\
\hline High & & & & \\
\hline
\end{tabular}

Based on the results of statistical calculations obtained conclusion that the ability of expressing generality of students on the numbers in high school is better than students in middle and low school level. However, the ability of expressing generalty of students in secondary schools did not differ significantly with low-level school students, although decryp- tively the average high school student score was higher than that of low-school students.

Problems related to the ability of expressing generality of numbers are number patterns, which in turn are expected to make an inductive conclusion of the patterns. The results of the analysis of the students' answers found that when the number patterns were performed at a limited stage, the students did so correctly. But when at a higher stage, students can not solve it. For example when given a problem:

Fill in the numbers on the blanks of the following equations,

$$
\begin{aligned}
& (1 \times 4)+2=(2 \times 3)+0 \\
& (2 \times 4)+2=(\ldots \times 3)+1 \\
& (\ldots \times 4)+2=(4 \times 3)+2 \\
& (4 \times 4)+2=(5 \times 3)+\ldots \\
& \ldots \ldots . . \\
& (54 \times 4)+2=(\ldots \times \ldots)+\ldots
\end{aligned}
$$

Almost all students answer correctly. But when the 5th row, almost all the students answered wrongly, although some students found in high school responded correctly on the 5th row, namely:

$$
(54 \times 4)+2=(55 \times 3)+53
$$


Type of student error as in the following figure.

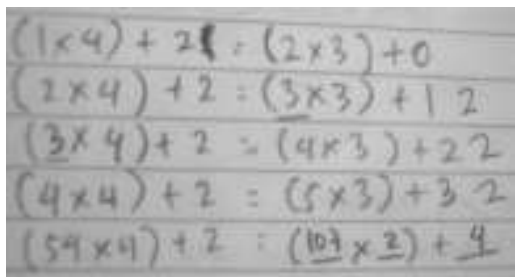

(a)

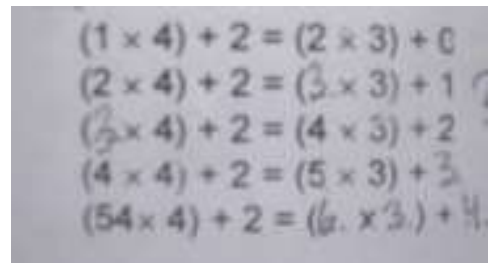

(b)

Figure 1 The Answer of the Wrong Student on Expressing Generality in Numbers

The student's answer as in Figure 1 (a) shows the student not using the pattern as in the previous rows, but using only the same number. The important result of the calculation on the left side is equal to the right side. Students who answer as in figure 1 (b) follow the pattern of the previous lines, but do not pay attention to the numbers on the pattern.

When given the following issues: Fill in the numbers on the blanks of the following equations.

$$
\begin{aligned}
& (2+1) \times(2-1)=2^{2}-1^{2} \\
& (4+2) \times(4-2)=4^{2}-2^{2} \\
& (6+4) \times(6-4)=\ldots-4^{2} \\
& (7+3) \times(7-3)=7^{2}-\ldots \\
& (21+5) \times(21-5)=\ldots-\ldots
\end{aligned}
$$

All students correctly answer the required points, but the above procedure is not used when the student solves the problem:

\section{Compute $42^{2}-32^{2}$}

If using the procedure, students will be easier to calculate, namely:

$42^{2}-32^{2}=(42+32) \times(42-32)=74 \times 10=740$

But the students finish it as follows.

$42^{2}-32^{2}=1764-1024=740$ by counting traditionally

This shows the pattern of student unused numbers in solving more difficult problems.
Furthermore, other issues related to the expressing generality of numbers are:

$$
\text { If } \quad \begin{aligned}
& 1 * 2=3 \\
& 2 * 3=8 \\
& 3 * 5=18 \\
& 4 * 7=32
\end{aligned}
$$

What $10 * 13$ ?

Students in low and middle school were unable to answer this question, but in high school there were some students who answered correctly.

Here is the correct student answer.

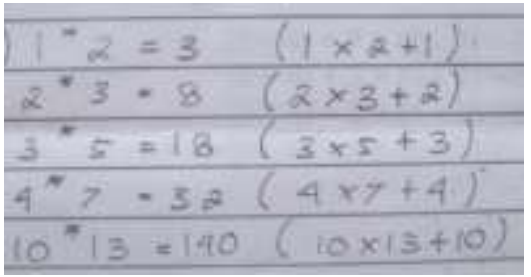

(a)

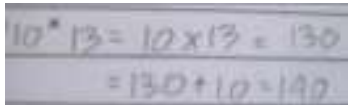

(b)

Figure 2 The Answer of the Right Studenton the Problem of Expressing Generality in Numbers

The first student answers perfectly, while the second student answers correctly, but the writing is wrong. The student error as in Figure 2 (b) violates the equivalence equivalents. In algebraic similarity is a statement where on both sides the similarity has the same value. The mistake made by students in line with Yumiati's statement [6], which is a common error in algebra is a way of writing that violates the equivalence of similarity.

\section{CONCLUSIONS AND SUGGESTIONS}

\section{A. Conclusions}

1. a. The students' Ability in Expressing Generality in Numbers scores at higher-level schools is greater than students in low and middle school. While the score of students' ability in expressing generality in middle and low school did not differ significantly.

b. The score of students' ability in expressing generality in numbers at the middle school was 5.79, while in low school was 5.44. Means, students' ability in expressing generality in numbers at middle and low school is the same. Therefore it is necessary to apply in the ability of expressing generality in numbers in middle school.

c. The students' ability scores in Expressing Generality in Numbers at all school levels are in enough categories. 
2. Inductive paradigms of students have not been good. Students can not make a general conclusion correctly.

\section{B. Suggestions}

1. The ability of students in expressing generality in numbers, especially students at low and middle school levels need to be improved again, in order to support algebraic thinking skills.

2. Need to improve teacher teaching methods that are student-oriented and complement various learning resources.

3. Further research needs to be done on appropriate learning methods to improve students' ability in expressing generality in numbers.

\section{REFERENCES}

[1] Dowker, A. (2008). Mathematical Difficulties Psychology and Intervention. Elsevier Inc.

[2] Dowker, A. (2004). What Works for Children with Mathematical Difficulties (Research Report RR554). Oxford: Department for Education and Skills.

[3] Ginsburg, H. P. (1997). Entering the Child's Mind: The Clinical Interview in Psychological Research and Practice. Cambridge, UK: Cambridge University Press.

[4] Jones, M. (1982). Children Written Representations of Number and Arithmetical Operations in a Communicatios Taks. Unpublished MSc. thesis, in University of Edinburgh.

[5] Hughes, M. (1986). Children and Number. Difficulties in Learning Mathematics. USA: Blackwell.
[6] Yumiati. (2013). "The Analysis Algebraic Thinking Skills of the Student in Secondari School". Makalah pada International Seminar Mathematics, Science, and Computer Science Education. UPI Bandung, tanggal 19 Oktober 2013.

[7] Yumiati (2015). Meningkatkan Kemampuan Berpikir Aljabar, Berpikir Kritis Matematis, dan Self Regulated Learning Siswa SMP Melalui Pembelajaran CORE (Connecting, Organizing, Reflecting, Extending). Disertasi. Sekolah Pascasarjana UPI Bandung. Tidak diterbitkan.

[8] Mason, J., Graham, A., and Willder, S.J. (2005). Developig Thinking in Algebra. London: Paul Chapman Publishing.

[9] Kieran, C. (2004). The Core of Algebra: Reflections on Its Main Activities. Boston: Kluwer Academic Publishers.

[10] Kriegler, S. (2011). Just What is Algebraic Thinking? [Online]. Tersedia: http:// introtoalg.com/downloads/articles01-kriegler.pdf. [5 Desember 2012].

[11] Haji, S. (2013). Pertanyaan Yang Memicu Kemampuan Berpikir Matematis Siswa dalam Pembelajaran Matematika. Prosiding Seminar Nasional Matematika dan Pendidikan Matematika STKIP Siliwangi Bandung.

[12] Chua, B.L. (2009). Features of Generalising Tasks. Help or Hurdle to Expressing Generality? Singapora: Nanyang Technological University. Amt 65(2) 2009/

[13] Mason, J., Burton, L., and Stacey, K. (2010). Thinking Mathematically. England: Pearson Education.

[14] Kilpatrick, J., Swafford, J., and Findell, B. (2001). Adding It Up: Helping Children Learn Mathematics. Wasington: National Academy Press.

[15] Haji, S. dan Yumiati (2011). Mengembangkan Kemampuan Berpikir Asli Melalui Pembelajaran Generatif dengan Pendekatan Open-Ended. Pasundan Journal of Mathematics Education. Tahun 1, Nomor 1, November 2011. 